\title{
Characterization of the $\mathrm{D}^{\prime \prime}$ beneath the Galapagos Islands using SKKS and SKS waveforms*
}

\author{
Elizabeth Vanacore ${ }^{1,2, \uparrow}$ and Fenglin $\mathrm{Niu}^{1}$ \\ ${ }^{1}$ Department of Earth Science, Rice University, Houston, TX 77005, USA \\ ${ }^{2}$ Research School of Earth Sciences, The Australian National University, Canberra, ACT 0200, Australia
}

\begin{abstract}
SKS and SKKS waveforms from 16 events occurring between 2003 and 2005 in the Tonga Trench that were recorded by the BOLIVAR array are analyzed to determine the structure of the $\mathrm{D}^{\prime \prime}$ layer beneath the Galapagos Islands. 248 differential travel-time residuals of SKKS-SKS are measured and reveal a region of positive residuals of differential travel times in the northeast portion of the sampled region. Analyzing correlation statistics between the measured SKKS-SKS residuals and the observed absolute travel time delay of the individual SKS and SKKS phases for two events with high data quality, we determine that the residual differential travel time is due to excess low velocity along the SKKS raypaths. First order modeling of three potential low velocity structures, ultra-low velocity zones (ULVZ), plume conduit, $\mathrm{D}^{\prime \prime}$ structure, indicates that the observed SKKS-SKS residuals can be best explained by a low velocity anomaly within the $\mathrm{D}^{\prime \prime}$ layer. To determine the presence of lower mantle anisotropy, amplitude ratios of the radial and transverse component of SKS and SKKS waveform are calculated and compared. Regions with significant presence of seismic anisotropy are interpreted as the edge of the flow field associated with a hypothetical mantle upwelling.
\end{abstract}

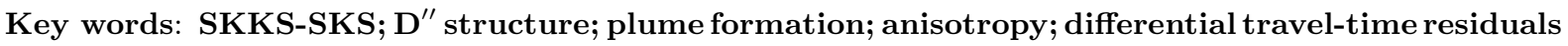
CLC number: P315.2 Document code: A

\section{Introduction}

Understanding the nature of the structure and dynamics of the $\mathrm{D}^{\prime \prime}$ layer is pertinent to our awareness of how this layer influences larger scale dynamics in the Earth's mantle. The $\mathrm{D}^{\prime \prime}$ region is of particular interest to Earth scientists as the layer is a probable graveyard for subducted oceanic lithosphere as well as a possible source region for mantle plumes (Christensen and Hofmann, 1994; Yuen and Peltier, 1980). While the $\mathrm{D}^{\prime \prime}$ layer has been extensively studied beneath Central America and the Caribbean (e.g., Hutko et al., 2006; Garnero and Lay, 2003; Lay et al., 2004a; Maupin et al., 2005; Rokosky et al., 2004; Reasoner and Revenaugh, 1999; Kendall and Shearer, 1994), the region directly underlying the Galapagos Islands has not been well

\footnotetext{
* Received 27 August 2010; accepted in revised form 4 January 2010; published 10 February 2011.

* Corresponding author. e-mail: elizabeth.Vanacore@anu.edu.au

(c) The Seismological Society of China and Springer-Verlag Berlin Heidelberg 2011
}

sampled by shear wave phases. Furthermore, recent geochemical measurements have indicated that the source of the Galapagos volcanism may be from a deep mantle plume source similar to the Hawaii and Samoa hotspots as it has a high $\mathrm{He}^{3} / \mathrm{He}^{4}$ ratio (Graham et al., 1993). The origin of hot spot volcanism and its associated geochemical signature in relation to mantle dynamics, however, has long been a debated subject. Some previous seismic, geochemical, and geodynamic studies present arguments supporting a deep mantle source for plume genesis (e.g., Montelli et al., 2004; Wen, 2006). Other recent studies, however, provide evidence that not all hot spots require a deep plume source or that OIB (ocean island basalt) formation does not require a distinct mantle chemical reservoir or a plume source (e.g., Courtillot et al., 2003; Meibom and Anderson, 2004). Recent seismic sampling of the mantle beneath the Galapagos Islands provides evidence for a plume source reaching depths greater than the transition zone (Hooft et al., 2003; Montelli et al., 2004). Finite fre- 
quency tomography imaging the hotspot provides evidence the plume conduit is nearly vertical from the surface to a depth of approximately $1000 \mathrm{~km}$ (Montelli et al., 2004). The primary objective of this study is to use SKS and SKKS waveforms that directly sample the $\mathrm{D}^{\prime \prime}$ directly beneath the Galapagos hotspot to search for evidence of a deep plume root.

The region sampled in this study is likely a seismically complex region as it is located near the edge of the large Pacific thermochemical pile (e.g., McNamara and Zhong, 2005) and is bounded to the Northeast by ancient subducted slab material beneath the Cocos Plate (e.g., Hutko et al., 2006; Garnero and Lay, 2003). As edges of thermochemical piles have been suggested to generate $\mathrm{D}^{\prime \prime}$ structures such as ultra low velocity zones by geodynamic studies (Hernlund and Tackley, 2007), our study region has high potential to sample such complex structure if it exists. Additionally, our study region's location is near the border between high velocity slab material and low velocity thermochemical pile material, where there likely exists a high lateral shear-wave velocity gradient that may lead to deep plume genesis in the region (Thorne et al., 2004). The potential seismic complexity of the region and its location near the border between the slab and the thermochemical pile regimes makes seismically characterizing the region's $\mathrm{D}^{\prime \prime}$ layer key to understanding the overall deep mantle dynamics and potential for plume genesis beneath the Galapagos Islands.

\section{Data and methods}

To characterize the CMB (core-mantle boundary) beneath the Galapagos Islands we use SKS and SKKS waveforms produced by 16 events in the Tonga Trench that were recorded by the BOLIVAR array in Venezuela and the western Caribbean between December 2003 and August 2005 (Table 1, Figure 1). This particular data set is unique in that the SKS and SKKS waveforms samples the $\mathrm{D}^{\prime \prime}$ both in the West Pacific and in the region about the Galapagos hotspot and northwestern South America. Moreover, the data samples azimuths in the SW-NE direction whereas most previous studies primarily sample at azimuths that are in the SE-NW or S-N directions (e.g., Ding and Helmberger, 1997; Garnero and Lay, 2003; Kendall and Nagini, 1996; Lay et al., 2004a; Maupin et al., 2005; Reasoner and Revenaugh, 1999; Thomas et al., 2004). To analyze and interpret the waveform data we exploit the fact that since the two phases sample the same region in the upper mantle and transition zone, measured residual SKKS-SKS differential travel times and differences anisotropy between the SKKS and SKS phases can be directly attributed to lower mantle structure.

\subsection{Residual differential travel time calcula- tions}

The raw broadband data is preprocessed with a bandpass filter using corner frequencies of $50 \mathrm{~s}$ and $2 \mathrm{~s}$ to enhance the SKS and SKKS arrivals. The exception

Table 1 Events used in this study

\begin{tabular}{|c|c|c|c|c|c|c|}
\hline \multirow{2}{*}{ Event } & \multirow{2}{*}{ Date } & \multicolumn{2}{|c|}{ Location } & \multirow{2}{*}{ Depth/km } & \multirow{2}{*}{$M_{\mathrm{W}}$} & \multirow{2}{*}{ Used in ratio? } \\
\hline & & Lat. $/{ }^{\circ} \mathrm{S}$ & Long. $/{ }^{\circ} \mathrm{E}$ & & & \\
\hline 1 & $2003-12-27$ & 21.67 & 169.83 & 10 & 6.7 & $\mathrm{~N}$ \\
\hline 2 & 2004-01-03 & 22.25 & 169.68 & 22 & 7.1 & $\mathrm{~N}$ \\
\hline 3 & 2004-01-25 & 16.83 & -174.20 & 129 & 6.7 & Y \\
\hline 4 & 2004-02-01 & 31.66 & 179.70 & 354 & 5.8 & $\mathrm{Y}$ \\
\hline 5 & 2004-03-09 & 32.27 & -178.36 & 18 & 6.2 & $\mathrm{~N}$ \\
\hline 6 & 2004-03-12 & 15.58 & -175.10 & 271 & 6.0 & $\mathrm{Y}$ \\
\hline 7 & 2004-03-18 & 23.76 & -176.00 & 10 & 6.2 & $\mathrm{~N}$ \\
\hline 8 & 2004-04-14 & 17.85 & -174.56 & 143 & 6.0 & $\mathrm{Y}$ \\
\hline 9 & 2004-10-08 & 10.95 & 162.16 & 36 & 6.8 & $\mathrm{~N}$ \\
\hline 10 & 2004-11-17 & 20.07 & -178.71 & 622 & 6.6 & $\mathrm{Y}$ \\
\hline 11 & 2004-11-21 & 15.40 & -174.91 & 256 & 6.0 & $\mathrm{Y}$ \\
\hline 12 & 2004-12-03 & 34.44 & 179.32 & 157 & 5.7 & $\mathrm{Y}$ \\
\hline 13 & $2004-12-17$ & 21.90 & -179.30 & 593 & 5.8 & $\mathrm{Y}$ \\
\hline 14 & $2005-01-16$ & 25.53 & -176.30 & 16 & 6.2 & $\mathrm{~N}$ \\
\hline 15 & 2005-03-19 & 21.90 & -179.55 & 598 & 6.3 & $\mathrm{Y}$ \\
\hline 16 & 2005-03-30 & 22.46 & -179.75 & 588 & 6.2 & $\mathrm{Y}$ \\
\hline
\end{tabular}




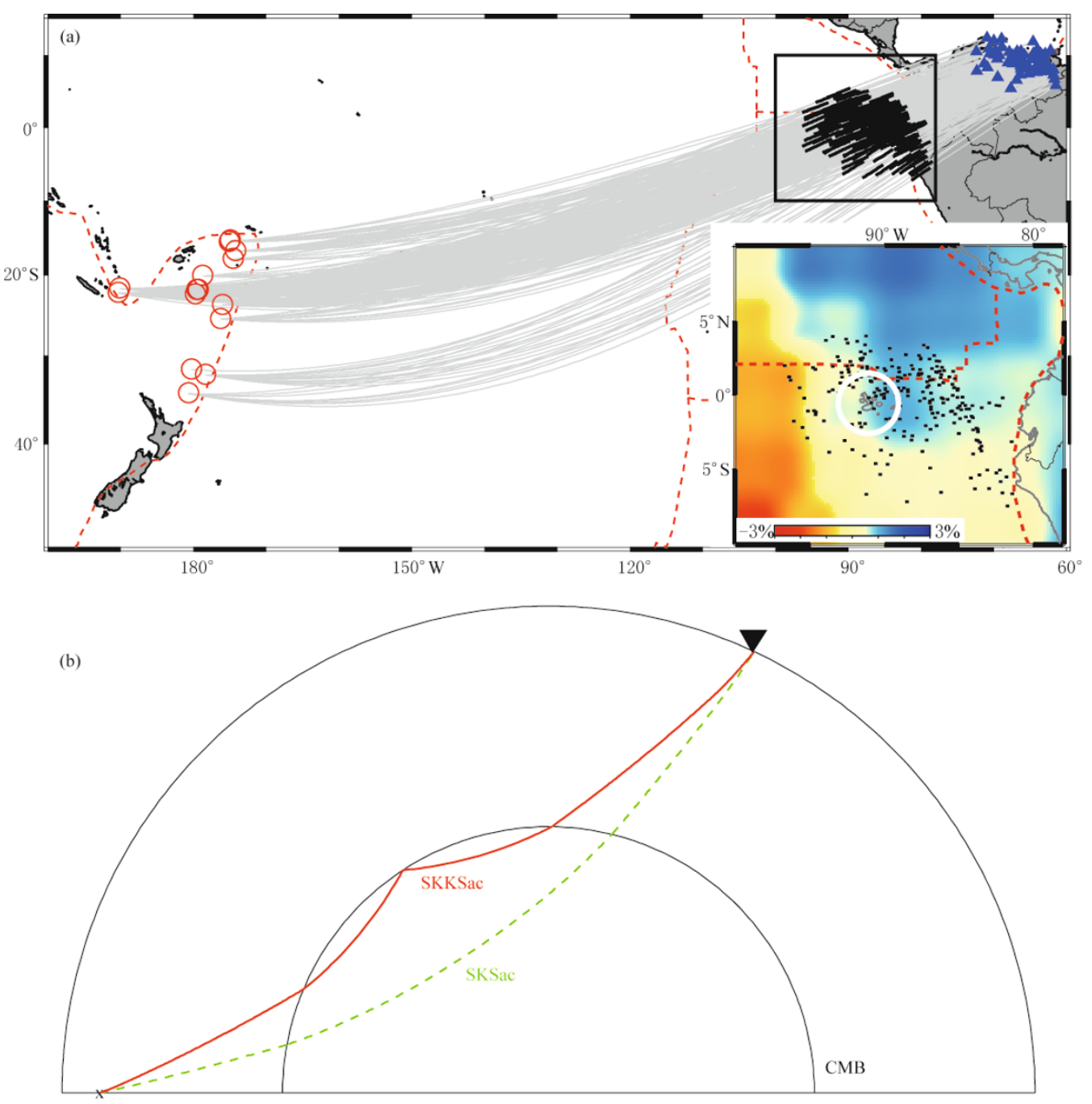

Figure 1 (a) Event (circles) and station (triangles) location are shown together with ray paths of the SKS and SKKS phases. Blacks lines show the SKKS ray segments in the $\mathrm{D}^{\prime \prime}$ layer in the receiver side. Inset shows the location of the Galapagos hotspot (white circle) and the CMB exit points of the SKKS ray paths (black squares), with a color background showing the S-wave velocity variations of Grand's S-wave tomographic model (2002). (b) Ray paths of SKS and SKKS.

to this preprocessing is the event occurring on March 30,2005 which was bandpass filtered with corner frequencies of $10 \mathrm{~s}$ and $2 \mathrm{~s}$ to remove a low frequency signal in the data that was obscuring the arrivals of the two phases of interest. Prior to calculating the differential travel time residuals a Hilbert transform is applied to the SKS waveform in order to account for the $\pi / 2$ shift between the SKS and SKKS phases. The residual differential travel time, $\delta T_{2 K-K}$, is calculated by subtracting calculated differential travel time of the PREM model (Dziewonski and Anderson, 1981) $\Delta T_{2 K-K}^{\text {prem from }}$ the observed one, $\Delta T_{2 K-K}^{\mathrm{O}}$. We further made a $3 \mathrm{D}$ correction computed from Grand's (2002) S-wave to- mographic model such that:

$$
\delta T_{2 K-K}=\Delta T_{2 K-K}^{\mathrm{O}}-\left(\Delta T_{2 K-K}^{\mathrm{prem}}+\Delta T_{2 K-K}^{3 \mathrm{DC}}\right) .
$$

The observed differential travel time $\left(\Delta T_{2 K-K}^{\mathrm{O}}\right)$ is measured by cross correlating the Hilbert transformed SKS waveform and SKKS waveform for each event station pair (Figure 2). To ensure stability of the cross correlation multiple time windows varying in length from 8 to 15 seconds were tested to check that the $\Delta T_{2 K-K}^{\mathrm{O}}$ values remained consistent; seismograms were additionally visually inspected to ensure the quality of the measured differential travel-time residuals. 


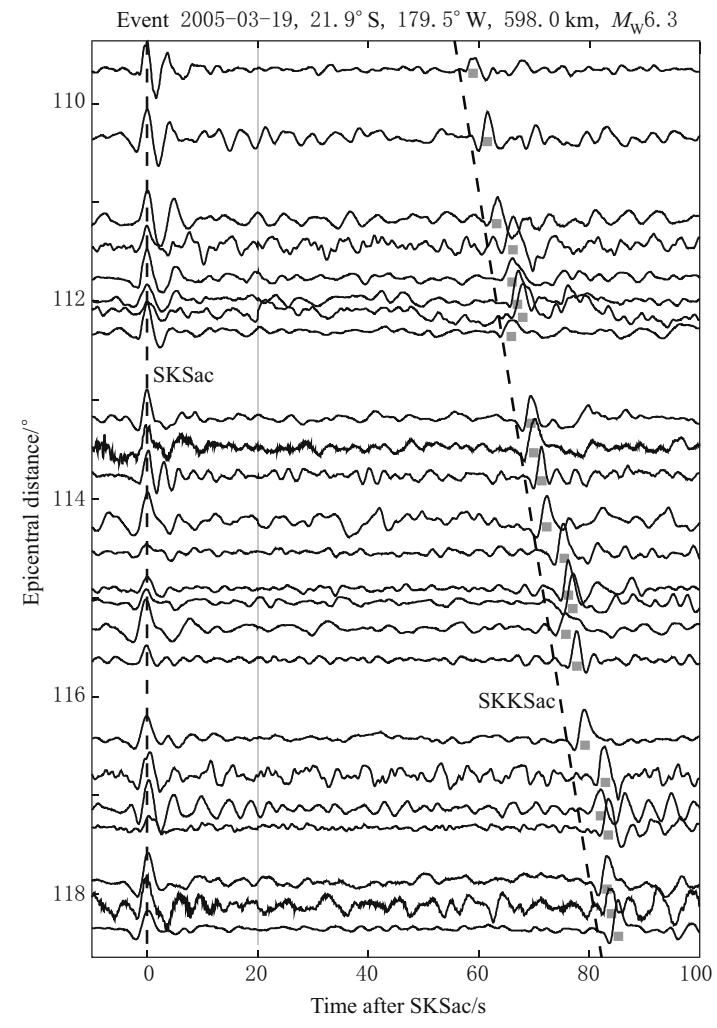

Figure 2 Unfiltered BOLIVAR seismograms plotted in order of epicentral distance for a deep event occurring in the Tonga Trench on March 18, 2005 aligned with respect to the SKS arrival time. The SKKS PREM theoretical arrival time and the actual arrival are denoted by the line and gray squares respectively. The SKS waveform is shifted by $\pi / 2$ via a Hilbert transform, so that the SKS and SKKS phases have the same waveform; the gray line at 20 seconds after the SKS arrival indicates the point at which the Hilbert transformed time series have been joined with the untransformed time series on the plot.

It is important to note that this methodology alone cannot distinguish between source side and receiver side anomalies as well as whether the anomalous velocity structure is along the SKS or SKKS raypath. In order to determine the nature of the residual time, other factors such as geographic distribution of the residuals and the correlation of the residuals to the individual SKS and SKKS travel time anomalies must be considered. The use and results of applying these controls to our data set will be discussed in detail later in this paper.

\subsection{Determining lower mantle anisotropy}

The concept of anisotropy in the $\mathrm{D}^{\prime \prime}$ layer is not new; multiple studies have examined shear wave phases that sample the lower mantle to determine the extent and amount of anisotropy in the deep mantle (e.g., Rus- sell et al., 1998; Fouch et al., 2001; Niu and Perez, 2004; Garnero et al., 2004a, b; Rokosky et al., 2006). In this study we exploit the fact that for a specific event and station pair, the SKS and SKKS, the shear wave splitting should be identical if the entire anisotropic component is restricted to the upper mantle. Hence, any difference between the measured shear-wave splitting, between the two phases from the dataset can be isolated to an anisotropic component in the lower mantle. The traditional method of measuring anisotropy by minimizing the energy of the tangential component (Silver and Chan, 1991) was applied to the data. However, the measured error yielded by the method for both phases was generally on the order of $\sim 22^{\circ}$ for the fast azimuth and $\sim 2 \mathrm{~s}$ for the time lag making the measurements unreliable for a direct comparison of SKS and SKKS anisotropy.

In order to derive an analogue for anisotropy, we examine the amplitude ratios of the SKKS and SKS phases for the radial and transverse components. We exploit the fact that upon leaving the core all the shear wave energy is limited to the radial component for the SKS and SKKS phases and that energy on the transverse component is due solely to anisotropy along the receiver side raypaths. While the individual amplitudes of the SKS and SKKS phases differ, the ratios of energy on the radial to transverse component of the SKS and SKKS waveforms for any station-event pair should be equal if the two phases only encounter anisotropy in the upper mantle. Deviations from this norm are therefore indicative of lower mantle anisotropy. The ratios are calculated by measuring picked peak amplitudes of the SKS and SKKS arrivals on both the radial and transverse components. The amplitude ratios are defined as follows:

$$
\begin{array}{r}
R_{1 \mathrm{~K}}=\mathrm{SKS}_{\mathrm{R}} / \mathrm{SKS}_{\mathrm{T}}, \\
R_{2 \mathrm{~K}}=\mathrm{SKKS}_{\mathrm{R}} / \mathrm{SKKS}_{\mathrm{T}}, \\
R=R_{2 \mathrm{~K}} / R_{1 \mathrm{~K}},
\end{array}
$$

where $\mathrm{SKS}_{\mathrm{R}}, \mathrm{SKS}_{\mathrm{T}}, \mathrm{SKKS}_{\mathrm{R}}$, and $\mathrm{SKKS}_{\mathrm{T}}$ are the measured amplitude of the indicated phase on the radial and transverse components respectively. Based on the ratio calculation when $R$, the final ratio measurement, has a value approximately equal to unity, this indicates that the entire shear wave splitting of both phases is due to anisotropy in the upper mantle. For analysis we limit the data set to seismograms that have an intermediate or deep source and have easily identifiable peak amplitudes. The data used in this processing is further limited to data for which both $R_{1 \mathrm{~K}}$ and $R_{2 \mathrm{~K}}$ are be- 
tween values of 0.5 to 2 ; this is to ensure that the two are comparable prior to calculating $R$. After applying these quality filters, the data is reduced from 248 measurements to 53 reliable amplitude ratio measurements for analysis.

\section{Results}

To examine the differential travel time residuals for the 16 events, 248 reliable measurements are plotted at the core-mantle boundary entrance and exit points for both the SKS and SKKS phases (Figure 3). Here we present our interpretation of these results considering the dataset as a whole rather than smaller subset of data. As with all differential travel-time residual data there is an element of non-uniqueness in the interpretation, tradeoffs between the amount of velocity perturbations on source and receiver side of the ray paths exist as the data represents the cumulative anomaly along the paths. With respect to the CMB entrance points the positive and negative residuals are intermixed within the same geographical region; this is especially evident with the SKKS entrance points along $150^{\circ} \mathrm{E}$ longitude (Figure 3 ). Conversely, the residuals plotted at the CMB exit points have a strong geographic pattern where the SKKS-SKS residuals become largely positive to the Northeast along either the SKKS or SKS raypaths with minimal mixing of the positive and negative residuals. Because this coherent pattern exists on the CMB exit (receiver) side for all the events in this study, we interpret that there is a velocity anomaly is located beneath the Galapagos or South America contributing to the observed residuals.

The data by themselves do not determine whether the positive SKKS-SKS residuals are due to a low velocity along the SKKS raypath or high velocity along the SKS raypath. To remove this ambiguity for the data simple statistics can be applied to explore the data set and differentiate between the anomaly sources. We examine two events, event \#15 and event \#16 occurring on March 19, 2005 and March 30, 2005 respectively, with the high quality data and a large station sampling of approximately 40 stations per event (Table 1). Because the observed differential travel-time residuals are sensitive to receiver velocity perturbations, there should exist a strong correlation between the residual and the arrival of the phase responsible for the residual. A similar method was applied by Russell et al. (1999) to successfully determine contribution of the $\mathrm{S}$ and $\mathrm{ScS}$ phase to observed differential travel time residuals. In order to perform the correlations, the excess travel time is calculated for the SKS and SKKS arrivals individually with respect to the 1D PREM model (Dziewonski and Anderson, 1981) and the 3D correction. These absolute travel time residuals are further processed by removing the mean for the data; this does not affect the correlations as it merely shifts the data to the region about a zero mean. The resultant plot of the absolute times versus the observed residuals (Figure 4) clearly shows a distinct relation between the SKKS phase and the residual differential travel time measurements. Additionally, the correlation coefficients for the two events corroborate the qualitative observations; the correlation coefficients for the SKS and SKKS phases are -0.08 and 0.61 for event \#15 and -0.02 and 0.52 for event \#16, respectively (Table 1 ). The extremely low correlation coefficients associated with the SKS phase is a strong indicator that observed residuals are not due to a high velocity anomaly along the SKS raypath. Whereas the stronger correlation of the differential travel-time residuals with the absolute SKKS travel times indicates there is a contribution from a low velocity structure along the SKKS raypath to the observed residual SKKS-SKS differential travel time measurements. The combination of the geographical analysis and the correlation statistics allow us to conclude the positive SKKS-SKS differential travel-time residuals are due to a low velocity perturbation in the lower mantle along the SKKS sampling region beneath the Galapagos Islands.

While it is tempting to immediately associate the low velocity perturbation to a structure in the $\mathrm{D}^{\prime \prime}$ such as a plume source region or ULVZ, one must note that the size, shape, and magnitude is not well defined by the differential travel-time residuals alone. Hence, we search for lower mantle anisotropy as a clue to further define the lower mantle structure in the region. Fiftythree reliable ratio measurements were obtained from the dataset and plotted at their geographic CMB exit points in Figure 5. The largest amplitude ratio variations between the two phases centered about $110^{\circ} \mathrm{E}$ longitude and $1^{\circ} \mathrm{N}$ latitude with respect to the SKKS CMB exit point. While possible influence of the BHR/BHT ratios due to different anisotropy due to active subduction beneath South America cannot be ignored, the ratio variations are assumed to be due to structure related to the SKKS raypath for the purposes of this study. Based on S wave tomography (Grand, 2002), SKS raypaths do not appear to sample significant slab material in the lower mantle or more specifically in the boundary layer between the mantle and core where detectable anisotropy would be easily detected (Montagner, 1998). 

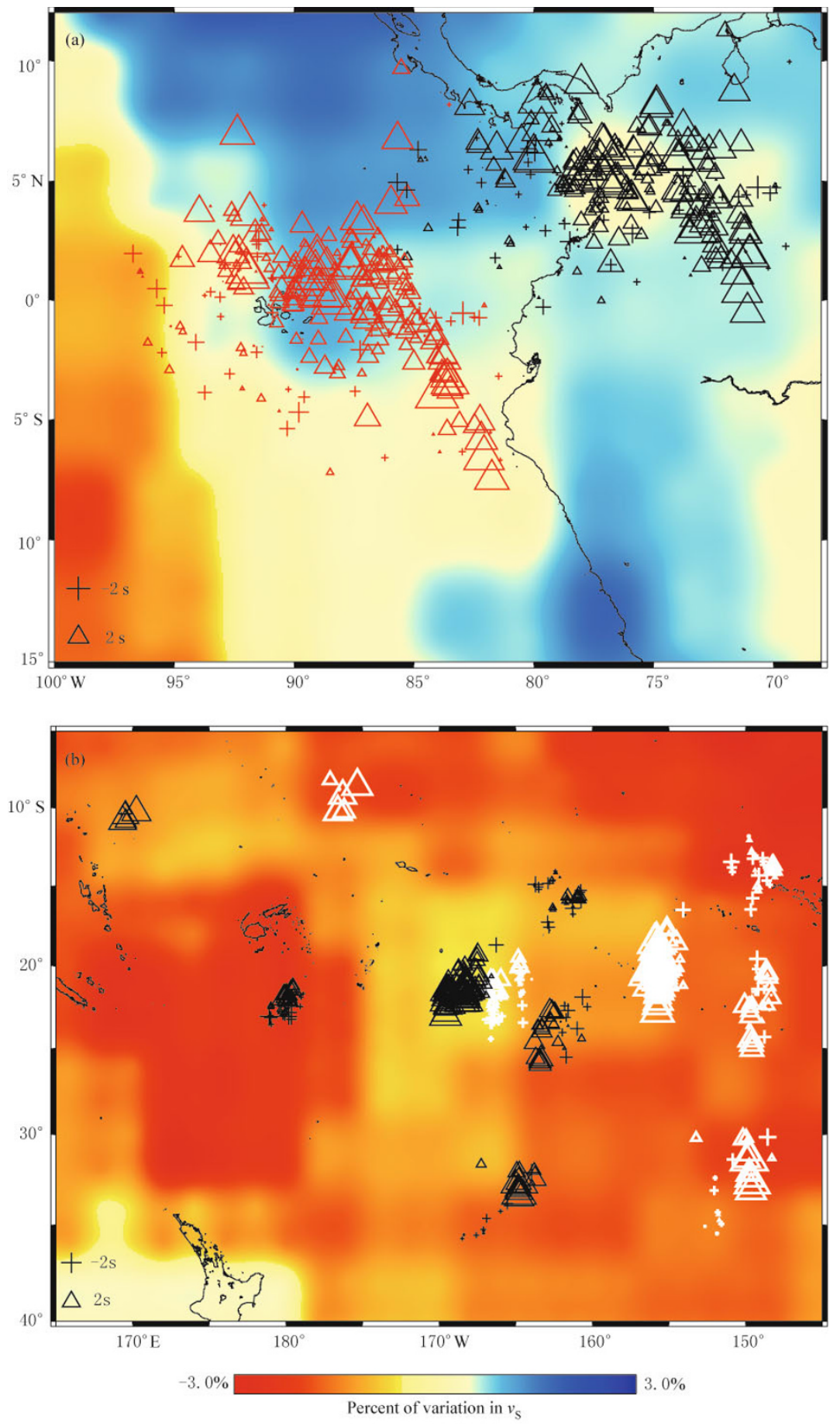

Figure 3 Geographic representation of approximately 248 SKKS-SKS differential travel time residuals measured in this study. A positive residual time indicates either a high velocity anomaly along the SKS raypath or a low velocity anomaly along the SKKS raypath. For our modeling purposes we assume the anomaly is caused by velocity perturbations along the SKKS raypath. (a) Residual differential times plotted with respect to the SKS (black) and SKKS (red) CMB exit points. The times increase along a path traveling from the SW to the NE. (b) Residual differential times plotted with respect to the SKS (black) and SKKS (white) CMB entrance points. The residual times do not have a cohesive pattern and in fact mix positive and negative differential times indicating that the anomaly is likely not caused by source side velocity perturbations. 

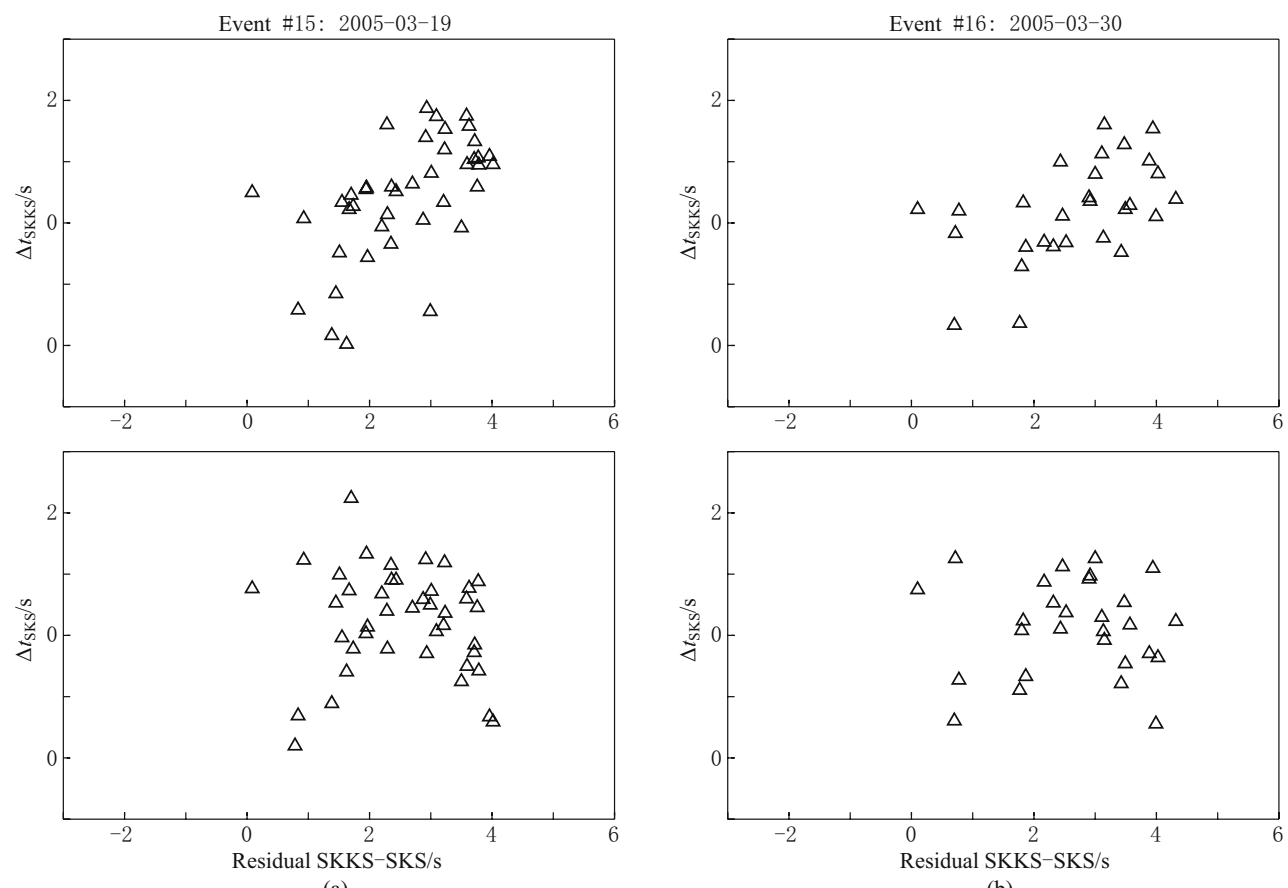

(a)

(b)

Figure 4 Correlation of the absolute travel time of the SKS and SKKS with the mean removed with the observed residual differential SKKS-SKS travel times for two high quality events, \#15 (a) and \#16 (b). For both events the SKS correlation is extremely weak while the SKKS correlation has a relatively stronger positive value. This implies that the velocity perturbation causing the observed differential travel-time residuals is due to excess low velocity sampled by the SKKS raypaths.

The SKKS raypaths, however, sample a complex region of the lower mantle where anisotropy is likely to be present due to the high potential for complex structure or mantle flow. Furthermore, recent mineralogical studies of the post perovskite phase indicate that within a downwelling slab strong anisotropy does not develop until it reaches the core mantle boundary (Merkel et al., 2007). There are two potential sources of anisotropy in the $\mathrm{D}^{\prime \prime}$ layer that would both influence SKS and SKKS shear wave splitting, LPO under the influence of lower mantle flows and the structural fabrics such as layers of melt or chemical heterogeneities (McNamara et al., 2001; Kendall and Silver, 1996; Williams and Garnero, 1996; Hall et al., 2004; Panning and Romanowicz, 2004). Lacking additional evidence supporting the presence of melt layers or other structural sources for anisotropy, we attribute the observations to LPO (lattice preferred orientation) for simple interpretation. The post perovskite phase develops lattice preferred orientation under pressure conditions present in the $\mathrm{D}^{\prime \prime}$ layer that can lead to significant anisotropy $(\mathrm{Mu}-$ rakami et al., 2004; Merkel et al., 2007).

Because the SKS and SKKS phases do not generate energy on the transverse component when the wave is traveling parallel to the principle axis of anisotropy, the measured ratios with a value near 1 have two possible interpretations. Since the raypaths have a similar azimuth throughout the data set, the ratio values near one may be attributed to the principle axis of anisotropy having a NE-SW alignment. The second possible explanation is that there is no lower mantle anisotropy in the regions where the ratios reach unity such as the area at $85^{\circ} \mathrm{W}$ longitude and $1^{\circ} \mathrm{S}$ latitude (Figure 5). Given the evidence for discrepancy between the SKS and SKKS anisotropy measurements through the majority of the study region and the low velocity anomaly in the region, the prior interpretation for the "null" ratios is preferred.

In order to better characterize the potential source for the observed residual SKKS-SKS travel time and BHR/BHT amplitude ratio data, we employ a simple forward modeling methodology to determine a feasible first order models of the low velocity zone. The main objective of this modeling is not to construct a comprehensive model of the detected low velocity but to identify the behavior of three end member regimes of lower mantle structure, an ultra low velocity zone at the base of the mantle, a large low velocity quadrant contained in the $\mathrm{D}^{\prime \prime}$ layer, and a vertical plume conduit through the lower mantle. The model space is defined by a three dimensional grid where each block is $0.5^{\circ} \times 0.5^{\circ} \times 50 \mathrm{~km}$ 


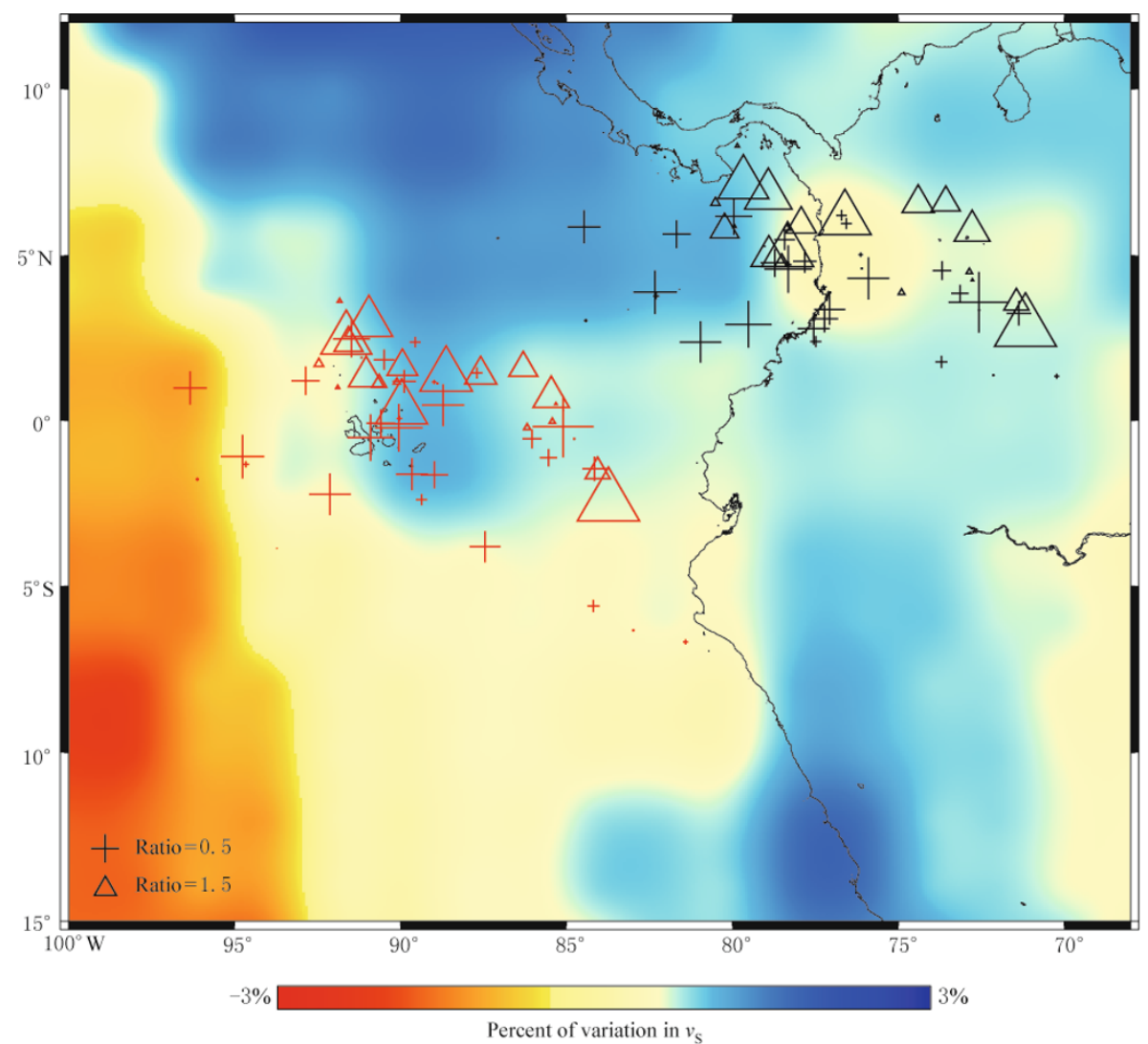

Figure 5 Results of the ratio analysis performed to retrieve an analogue for anisotropy plotted at the CMB exit points of the SKS (black) and SKKS (red) phases. In this figure smaller symbols denote a ratio values near 1 ; the symbols increase in size as the deviation from a ration value of 1 increases. Note the ratios mimic the pattern observed in the residual differential travel time analysis (see Figure 3) and the concentration of amplitude ratio variation between the SKKS and SKS phase observed near $\left(1^{\circ} \mathrm{S}, 90^{\circ} \mathrm{W}\right)$. We interpret this anomaly as a possible northwestern edge of a mantle upwelling in the $\mathrm{D}^{\prime \prime}$ layer.

and each grid point contains the velocity perturbation information. In order to effectively model a thin ULVZ of $50 \mathrm{~km}$ at the base of the mantle, we decrease the vertical dimension of the grid to $25 \mathrm{~km}$ so that there are multiple grid points sampled within the anomaly. Because the objective of this modeling is to calculate the differential travel time residuals, model velocity perturbations with respect the $1 \mathrm{D}$ background model (PREM) were limited to the constructed anomaly. To calculate the predicted change in travel time due to the modeled perturbation, we use the raypath approximation of the SKKS phase to calculate a 3D travel time correction for the model space. Because the only velocity perturbation in the model is the constructed anomaly, the calculated $3 \mathrm{D}$ correction is equivalent to the residual differential travel time caused by low velocities along the raypath. While a small suite of different geometries and anomaly geographic locations was cal- culated for type of model, here we show only three of the end member models that are representative of the behavior for each model category.

To simulate a ULVZ beneath the Galapagos, we define a best fit model with a low velocity anomaly of $50 \mathrm{~km}$ thickness with a $30 \%$ decrease of shear wave velocity bounded by $88^{\circ} \mathrm{W}$ to the West, $87^{\circ} \mathrm{W}$ to the East, $5^{\circ} \mathrm{S}$ to the South, and $5^{\circ} \mathrm{N}$ to the North. The anomaly is designed with these by choosing the largest feasible velocity perturbation and largest predicted thickness of an ULVZ (Garnero, 2000, 2004; Lay et al., 2004b) as parameters in order to maximize the possible effect of the velocity anomaly on the calculated residual travel time. At these extreme values the ULVZ model can produce a travel time anomaly on the scale of the observations but is restricted to a localized region in map view roughly bound by the prescribed anomaly (Figure 6a). The calculated residuals are binned in $1^{\circ}$ 
bins at a $0.5^{\circ}$ along a transect crossing the region at a $45^{\circ}$ angle and centered at the surface expression of the hotspot at $\left(91^{\circ} \mathrm{W}, 0^{\circ}\right)\left(A A^{\prime}\right.$ in Figure $\left.6 \mathrm{a}\right)$, the predicted residuals excluding null observation mimic the pattern formed by the observed differential travel-time residuals (Figures 6a, 6d). Despite mimicking the pattern produced the geographic extent of the anomaly is inconsistent with the observed residual SKKS-SKS differential travel times. An extensive ULVZ in the region would require a much thinner ULVZ and lower velocity perturbation to match the geographic extent, but such
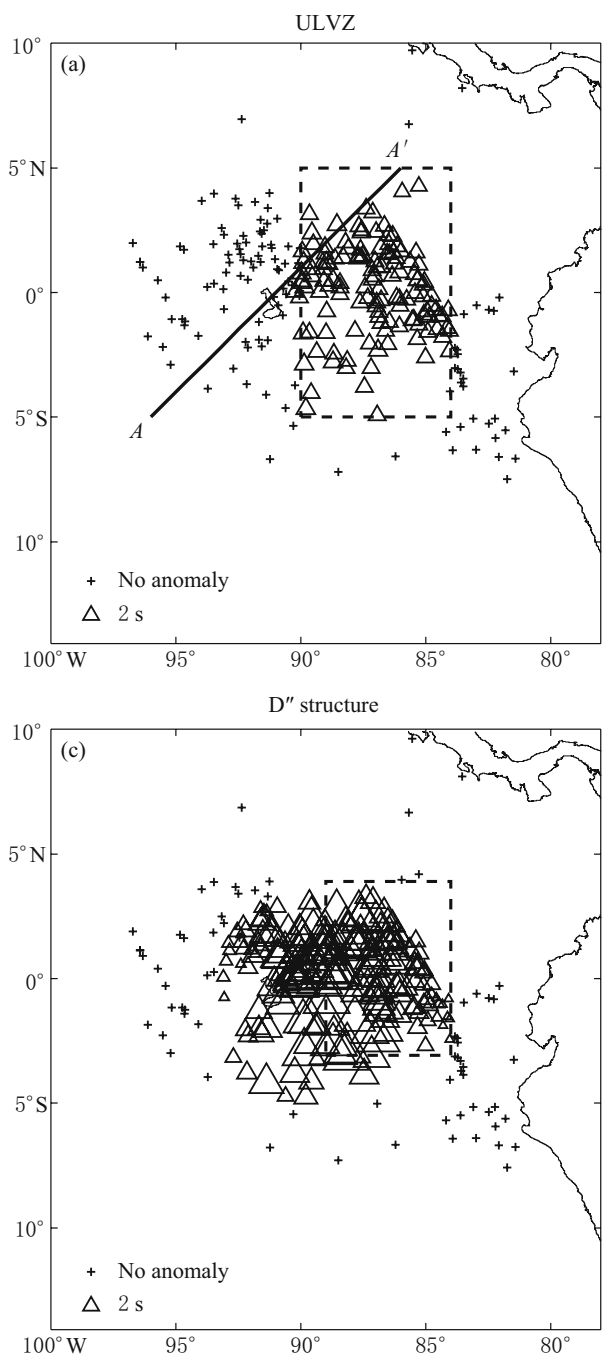

a model would also result in a broadening and flattening of the concave shaped observed along transect $A A^{\prime}$. Because the ULVZ does not match both the geographic extent and the transect pattern along $A A^{\prime}$, this model is not the preferred interpretation.

We now examine the effect of a plume conduit in the lower mantle ignoring the existence of a plume root as this is defined in our modeling process as a part of structure in $\mathrm{D}^{\prime \prime}$. The model is once again designed to maximize the effect of the low velocity perturbation in the lower mantle so that the overall influence of this
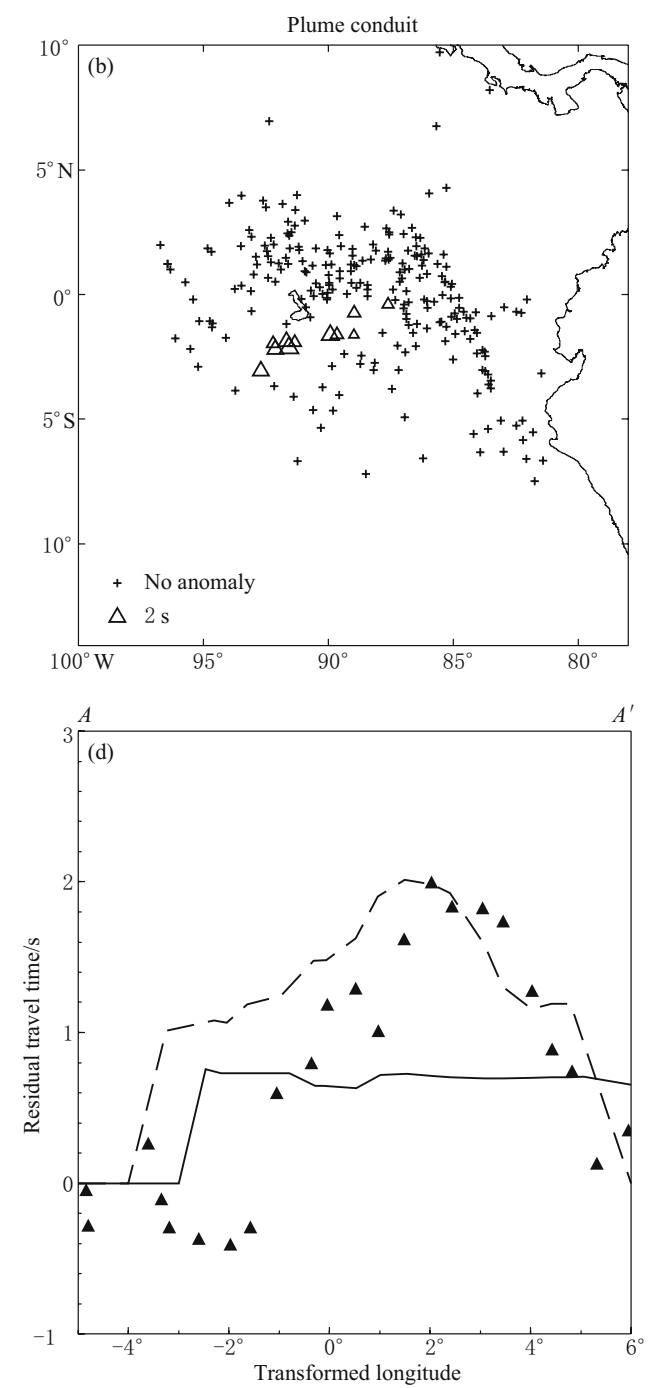

Figure 6 Three representative results from the diagnostic modeling of general types of potential low velocity structure in the lower mantle. The box in each map indicates the geographic extend of the modeled low velocity anomaly. (a) Map view of results from a model ULVZ with a velocity perturbation of $-30 \%$ limited to the lowermost $50 \mathrm{~km}$ of the mantle. The line $A A^{\prime}$ is the transect used for the binned data shown in $6 \mathrm{~d}$. (b) Map view of results for a $1^{\circ}$ diameter vertical plume conduit with a velocity perturbation of $-5 \%$. (c) Map view of results for a low velocity structure limited to the $\mathrm{D}^{\prime \prime}$ structure with a velocity perturbation of $-5 \%$. (d) The transect $A A^{\prime}$ showing the observed data (triangles) and results from the ULVZ (solid line) and $\mathrm{D}^{\prime \prime}$ low velocity (dashed line) models binned at $0.5^{\circ}$ intervals and $1^{\circ}$ bins. Note that for the models null observations are ignored. 
type of structure can be determined. To demonstrate this influence we show results from a model in which a vertical plume conduit with a $1^{\circ}$ diameter centered at $\left(87.5^{\circ} \mathrm{W}, 0.5^{\circ} \mathrm{S}\right)$ is given a modest $5 \%$ velocity reduction (Figure 6b). This model does not account for complications of plume conduit such as tilting or split up (e.g., Steinberger and O'Connell, 1998) because the potential root of the system is located nearly directly beneath the surface expression of the hot spot, so these complications are unlikely. The results from this model indicate that a plume conduit in the lower mantle has little influence on the residual SKKS-SKS differential travel times. Indeed, the velocity perturbation only influences raypaths that sample either directly beneath or to the southwest of the conduit (Figure 6b). The limited influence to the southwest specifically beyond the Galapagos Islands signifies that a larger anomaly in the lower mantle would lead to an overestimation of differential travel-time residuals in that region. A smaller plume conduit of the order of $50 \mathrm{~km}$ in diameter would show even less influence on the differential travel-time residuals. Hence, this model does not exclude a plume conduit in the lower mantle, but does eliminate the probability of large scale low velocity in the region between the $\mathrm{D}^{\prime \prime}$ and $660 \mathrm{~km}$ discontinuity.

To test the probability that the differential travel time observations are due to low velocity structure limited to the $\mathrm{D}^{\prime \prime}$ region, we limit a $5 \%$ velocity reduction to structure to mantle depths greater than $2650 \mathrm{~km}$ and a regular rectangular region. Limiting the shape of the region will allow a first order test on whether structure in the $\mathrm{D}^{\prime \prime}$ can roughly mimic our observations. The trades off of velocity perturbation, layer thickness, and geographic complexity are not explored in this modeling exercise as the best fit model would retain large amounts of non-uniqueness and is beyond the scope of determining the first order location of the velocity anomaly along the SKKS raypaths. The model results shown in Figures $6 \mathrm{c}-6 \mathrm{~d}$ are for a geographic region bound by $89^{\circ} \mathrm{W}$ to the west, $84^{\circ} \mathrm{W}$ to the east, $3^{\circ} \mathrm{S}$ to the south, and $4^{\circ} \mathrm{N}$ to the north. The model while not a best fit model to the data shows two important characteristics. One, the size of the differential travel-time residuals calculated by the model is of the same scale as the observed SKKSSKS data. Two, the calculated data when binned along the transect $A A^{\prime}$ show the same general characteristic pattern as the observed data where there is a gradual transition to a peak residual before a decreasing rapidly (Figure 6). The two similarities indicate that the observed SKKS-SKS differential travel-time residuals are due to velocity perturbations limited primarily to the $\mathrm{D}^{\prime \prime}$ layer.

\section{Discussion}

The combined observations of the low velocity along the SKKS raypath, the limitation of this velocity to the $\mathrm{D}^{\prime \prime}$ via diagnostic modeling, and the presence of anisotropy in the region provide important clues for interpreting lower mantle structure in this presumably complex region. Multiple studies to the northeast of the study region have characterized regional anisotropy and high velocity structures associated with ancient subducted slab material (e.g., Hutko et al., 2006; Garnero and Lay, 2003; Lay et al., 2004a; Maupin et al., 2005; Rokosky et al., 2004; Reasoner and Revenaugh, 1999; Kendall and Shearer, 1994). Of particular interest is the study by Hutko et al. (2006) as it not only identifies the structure of the slab beneath the Cocos Plate, but also identifies the presence of a low velocity structure southwest of the slab edge. The existence of this identified structure heeds credence to the observed low velocity structure in this study. The well-established high velocity to the northeast (e.g., Garnero and Lay, 2003) provides an a priori border to the extent of the low velocity region observed in this study. Applying this "border" to the observed residual SKKS-SKS differential travel times in this study, we can roughly limit the anomaly to the region bounded to the west by the observed change in residual differential travels times southwest of the Galapagos Islands (Figure 2) and to the north by approximately $5^{\circ} \mathrm{N}$ latitude. The bounds to the south and directly east are not well constrained by this data set or previous studies of the $\mathrm{D}^{\prime \prime}$ in the region; determining the southern and eastern bounds of this relatively small low velocity structure requires additional data and merits further study.

We now consider the more qualitative anisotropy data in combination with the inferred low velocity anomaly. Assuming the anisotropy is due to structure caused by mantle flow at the base of the mantle that is likely present along the SKKS ray path and the low velocity environment, the cluster of observed differential anisotropy indicates the region may be the edge source of local upwelling where the local flow pattern is oriented in the NW-SE direction. The region sampled in this study is the border between two distinct environments, the ancient subducted slab to the West (e.g., Hutko et al., 2006; Garnero and Lay, 2003; Lay et al., 2004a; Maupin et al., 2005; Rokosky et al., 2004; Rea- 
soner and Revenaugh, 1999; Kendall and Shearer, 1994) and the edge of the Pacific thermochemical pile to the East (McNamara and Zhong, 2005), which places the region under convergent flow in the NW-SE direction. The convergent flow in such an environment makes it a prime target for the formation of ULVZ's and a source of upwelling in the mantle (e.g., Hernlund and Tackley, 2007). Based on our sampling azimuths, we would expect splitting of energy due to lower mantle structure to the transverse component to be weak or variable where the flow is in the NE-SW direction or is upwelling because energy along the direction of flow or parallel to the principle axes will not produce splitting in the SKS or SKKS phases (Hall et al., 2004). If we assume the differences in anisotropy occur in the SKKS raypath, the observations indicate that the highest potential for plume formation at the base of the mantle is located to the west or southwest of the Galapagos Island's surface location.

Given the detected low velocity and the evidence for lower mantle shear wave splitting beneath the Gala- pagos, a hypothetical $\mathrm{D}^{\prime \prime}$ layer structure can be formulated. From the low velocity along the SKKS raypath and differences in shear wave splitting we hypothesize that an upwelling is centered near the geographic point $\left(1^{\circ} \mathrm{S}, 87^{\circ} \mathrm{W}\right)$ between the slab remnant to the northeast and the thermochemical pile to the west. The validity of this hypothesis is testable given more data specifically sampling this border region between the two large scale structures. Key to confirming or rejecting this hypothesis is determining the borders of the low velocity structure to the East and South. If the low velocity signature is due to upwelling and possible plume genesis, then the structure should be limited in size. As with the northern or western borders, there should be a switch back to high velocity structures within a couple hundred kilometers to the south and east of the region sample in this study. The second key to confirming or rejecting this hypothesis is determining the detailed $\mathrm{D}^{\prime \prime}$ flow structure in this border region; a schematic of predicted mantle flow based on our hypothesis is presented in Figure 7. If the same methodology and same relative
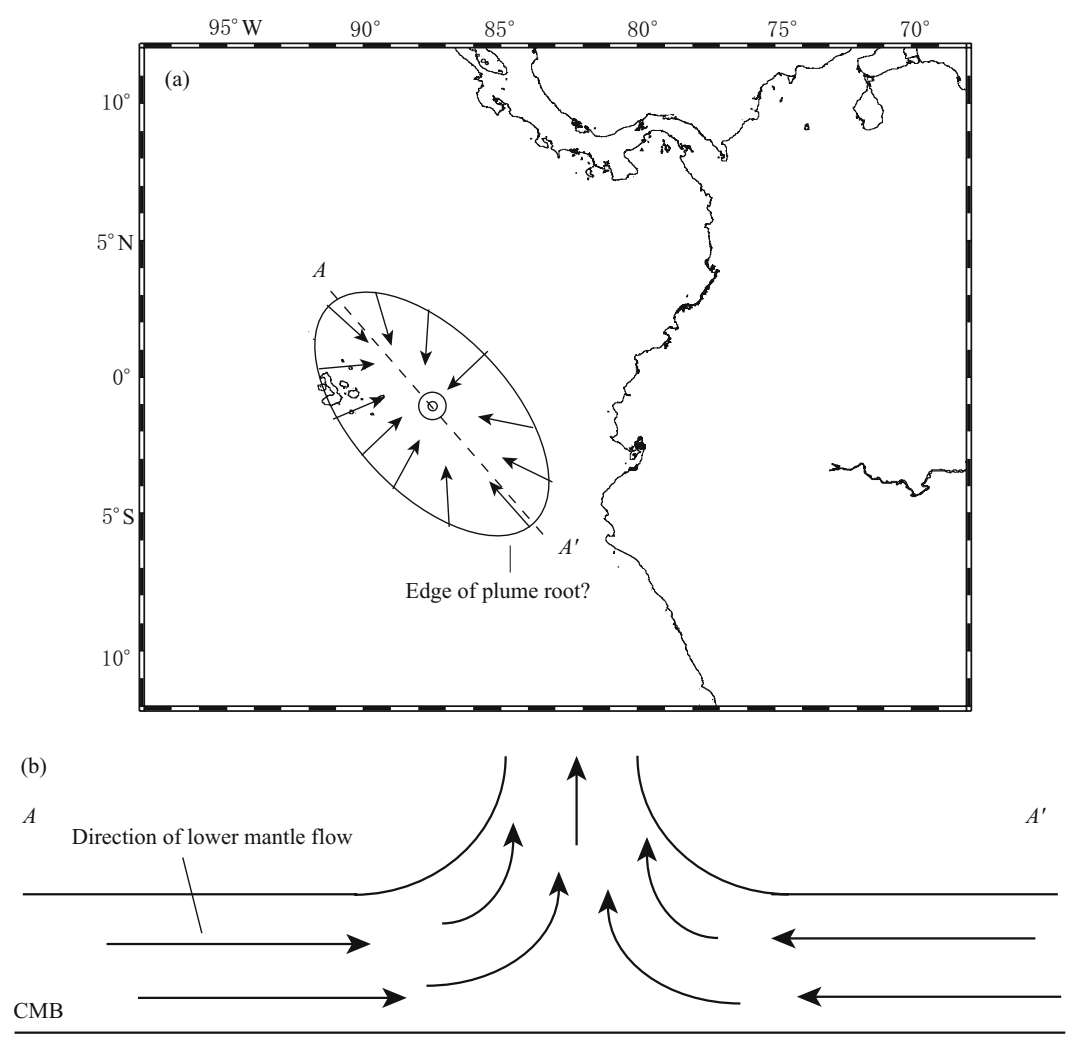

Figure 7 Schematic of predicted $\mathrm{D}^{\prime \prime}$ flow if the low velocity structures observed are due a plume root. (a) Map view of the mantle flow; upward flow is indicated by the circle. $A A^{\prime}$ denotes the cross sectional view shown in Figure 7b. (b) Cross section view of the predicted flow field along $A A^{\prime}$. 
azimuths to determine the extent of differential shear wave splitting, then we would expect to observe a region of high differentials to the southeast demarking the southeastern border of the upwelling. Measurements of deep mantle anisotropy have been successful in determining lower mantle structure previously to find the root Hawaiian plume and the structure of low velocity provinces (e.g., Russell et al., 1998; Fouch et al., 2001; Wang and Wen, 2007); determining if there is upwelling in this region would yield evidence for or against a plume root to the southeast of the Galapagos Islands. Such high quality measurements of anisotropy in the region with a greater azimuthal sampling would provide a definitive flow structure for the region providing critical understanding to the dynamics of this border region and consequently the interaction of slab material and thermochemical piles in the deep mantle.

\section{Conclusions}

In this study we analyzed SKS and SKKS waveforms from 16 events in the Tonga Trench recorded by the BOLIVAR array in Venezuela and southern Caribbean between 2003 and 2005. The region is unique and critical to the understanding of larger scale mantle dynamics and plume formation as it is located on the border between the large thermochemical pile in the Pacific and remnants of ancient subducted slab to the Northeast (McNamara and Zhong, 2005; Hutko et al., 2006; Garnero and Lay, 2003). Calculation of SKKSSKS residual differential travel time yielded evidence of a low velocity zone east of the Galapagos Islands as correlation statistics of the residuals and the absolute travel times of the individual phases constrain the velocity perturbation to the region sampled by the SKKS raypaths. Modeling of three diagnostic types of structures, a ULVZ, a plume conduit, and a $\mathrm{D}^{\prime \prime}$ layer structure, yields information that the observations are influenced primarily by structure in the $\mathrm{D}^{\prime \prime}$ layer. Using an analysis of amplitude ratios, it was determined that azimuthal anisotropy is present in the region and may demark the edge of an upwelling structure beneath the Galapagos. We hypothesize that a plume root is present at the base of mantle likely centered near $\left(1^{\circ} \mathrm{S}, 87^{\circ} \mathrm{W}\right)$ as a consequence of the compression of $\mathrm{D}^{\prime \prime}$ material between the thermochemical pile to the west and the sweeping of the ancient subducted slab to the Northeast. In order to confirm or reject this hypothesis determining the flow pattern from more detailed anisotropic measurements and the locating the edges of the $\mathrm{D}^{\prime \prime}$ low velocity anomaly to the east and south are critical. Obtaining and analyzing data that samples the border region in detail from multiple azimuths is a goal worthy of further study.

Acknowledgements We would like to acknowledge Garnero E. J. and the anonymous reviewers for their helpful comments and advice. The figures in this paper were generated using GMT developed by P. Wessel and W. H. F. Smith.

\section{References}

Christensen U R and Hofmann A W (1994). Segregation of subducted oceanic crust in the convecting mantle. $J$ Geophys Res 99: 19867-19 884.

Courtillot V, Davaille A, Besse J and Stock J (2003). Three distinct types of hotspots in the Earth's Mantle. Earth Planet Sci Lett 205: 295-308.

Ding X and Helmberger D (1997). Modeling D" structure beneath Central America with Broadband Seismic Data. Phys Earth Planet Interi 101: 245-270.

Dziewonski A M and Anderson D L (1981). Preliminary reference earth model (prem). Phys Earth Planet Inter 25: 297-356.

Fouch M J, Fischer K M and Wysession M E (2001). Lowermaost mantle anisotropy beneath the Pacific: Imaging the source of the Hawaiian plume. Earth Planet Sci Lett 190: $167-180$.

Garnero E J (2000). Heterogeneity of the lowermost mantle. Ann Rev Earth Plant Sci 28: 509-537.

Garnero E J (2004). A new paradigm for Earth's coremantle boundary. Science 304: 834-836.

Garnero E J and Lay T (2003). D" shear velocity heterogeneity anisotropy and discontinuity structure beneath the Caribbean and Central America. Phys Earth Planet Interi 140: 219-242.

Garnero E J, MaupinV, Lay T and Fouch M (2004a). Variable azimuthal anisotropy in Earth's lowermost mantle. Science 306: 250, doi:10.1126/science.1103411.

Garnero E J, Moore M M, Lay T and Fouch M J (2004b). Isotropy or weak vertical transverse isotropy in $\mathrm{D}^{\prime \prime}$ beneath the Atlantic Ocean. J Geophys Res 109: B08308, doi:10.1029/2004JB003004.

Graham D W, Christie D M, Harpp K S and Lupton J E (1993). Mantle plume helium in submarine basalts from the Galpagos Platform. Science 262(5142): 2023 , doi:10.1126/science.262.5142.2023.

Grand S P (2002). Mantle shear-wave tomography and the fate of subducted slabs. Phil Trans $R$ Soc Lond 360: $2475-2491$.

Hall S A, Kendall J M, van der Baan M (2004). Some comments on the effects of lower mantle anisotropy on the SKS and SKKS phase. Phys Earth Planet Inter 146: 
469-481.

Hernlund J W and Tackley P J (2007). Some dynamical consequences of partial melting in Earth's deep mantle. Phys Earth Planet Inter 162(1-2): 149-163, doi:10.1016/j.pepi.2007.04.005.

Hooft E E E, Toomey D and Solomon S C (2003). Anomalously thin transition zone beneath the Glapagos hotspot. Earth Planet Sci Lett 216: 55-64.

Hutko A R, Thorne L, Garnero E J and Revenaugh J (2006). Seismic detection of folded, subducted lithosphere at the core-mantle boundary. Nature 441(7091): 333-336.

Kendall J M and Shearer P M (1994). Lateral variations in $\mathrm{D}^{\prime \prime}$ thickness from long-period shear wave data. $J$ Geophys Res 99(B6): 11 575-11 590.

Kendall J M and Silver P (1996). Constraints from seismic anisotropy on the nature of the lowermost mantle. Nature 381: 409-412.

Kendall J M and Nagini C (1996). Lateral Variations in D" below the Caribbean. Geophys Res Lett 23(4): 399-402.

Lay T, Garnero E J and Russell S A (2004a). Lateral variation of the $\mathrm{D}^{\prime \prime}$ discontinuity beneath the Cocos Plate. Geophys Res Lett 31: L15612, doi:10.1029/ 2004GL020300.

Lay T, Garnero E J and Williams Q (2004b). Partial melting in a thermo-chemical boundary layer at the base of the mantle. Phys Earth Planet Inter 146: 441-467.

Maupin V, Garnero E J, Lay $\mathrm{T}$ and Fouch M J (2005). Azimuthal anisotropy in the $\mathrm{D}^{\prime \prime}$ layer beneath the Caribbean. J Geophys Res 110: B08301, doi: 10.1029/2004JB003506.

McNamara A K, Karato S and van Keken P (2001). Localizaton of dislocation creep in the lower mantle: implications for the origin of seismic anisotropy. Earth Planet Sci Lett 191: 85-99.

McNamara A K and Zhong S (2005). Thermochemical structures beneath Africa and the Pacific Ocean. $\mathrm{Na}$ ture 437(7062): 1136-1 139, doi:10.1038/nature04066.

Merkel S, McNamara A K, Kubo A, Speziale S, Miyagi $\mathrm{L}$ and Meng Y (2007). Deformation of $(\mathrm{Mg}, \mathrm{Fe}) \mathrm{SiO}_{3}$ post-perovskite and $\mathrm{D}^{\prime \prime}$ anisotropy. Science $\mathbf{3 1 6}(5832)$ : 1729-1 732.

Meibom A and Anderson D L (2004). The statistical upper mantle assemblage. Earth Planet Sci Lett 217(1-2): 123-139.

Montagner J (1998). Where can seismic anisotropy be detected in the Earth's mantle? In boundary layers; geodynamics of lithosphere and Earth's mantle; seismic anisotropy as a record of the past and present dynamic processes. Pure Appl Geophys 151(2-4): 223-256.

Montelli R, Nolet G, Dahlen F A, Masters G, Engdahl E $\mathrm{R}$ and Hung $\mathrm{S}$ (2004). Finite frequency tomography reveals a variety of plumes in the mantle. Science 303: 338-343.

Murakami M, Hirose K, Kawamura K, Sata N and Ohishi $\mathrm{Y}$ (2004). Post-perovskite phase transition in $\mathrm{MgSiO}_{3}$.
Science 304(5672): 855-858.

Niu F and Perez A M (2004). Seismic anisotropy in the lower mantle: a comparison of waveform splitting of SKS and SKKS. Geophys Res Lett 31(24): 4.

Panning M and Romanowicz B (2004). Inferences on flow at the base of the Earth's mantle based on seismic anisotropy. Science 303: 351-53.

Reasoner C and Revenaugh J (1999). Short-period P wave constraints on $\mathrm{D}^{\prime \prime}$ reflectivity. J Geophys Res 104(B1): 955-961.

Rokosky J M, Lay T, Garnero E J and Russell S A (2004). High-resolution Investigation of shear wave anisotropy in $\mathrm{D}^{\prime \prime}$ beneath the Cocos Plate. Geophys Res Lett 31: L07605, doi: 10.1029/2003GL018902.

Rokosky J M, Lay T and Garnero E J (2006). Small-scale lateral variations in azimuthally anisotropic $\mathrm{D}^{\prime \prime}$ strudture beneath the Cocos Plate. Earth Planet Sci Lett 248: 411-425.

Russell S A, Lay T and Garnero E J (1998). Seismic evidence for small-scale dynamics in the lowermost mantle at the root of the Hawaiian hotspot. Nature 396: 255258.

Silver P G and Chan W W (1991). Shear wave splitting and subcontinental mantle deformation. J Geophys Res $\mathbf{9 6}$ : $16429-16454$.

Steinberger B, and O'Connell R J (1998). Advection of plumes in mantle flow: implications for hotspot motion, mantle viscosity and plume distribution. Geophys J Inter 132(2): 412-434, doi: 10.1046/j.1365-246x. 1998.00447.x.

Thomas C, Garnero E J and Lay T (2004). Highresolution imaging of lowermost mantle structure under the Cocos plate. J Geophys Res 109: B08307, doi: 10.1029/2004JB003013.

Thorne M S, Garnero E J and Grand S P (2004). Geographic correlation between hot spots and deep mantle lateral shear-wave velocity gradients. Phys Earth Planet Inter 146: 47-63.

Wang Y and Wen L (2007). Complex seismic anisotropy at the border of a very low velocity province at the base of the Earth's mantle. J Geophys Res 112: B09305, doi:10.1029/2006JB004719.

Williams Q and Garnero E J (1996). Seismic evidence for partial melt at the base of the Earth's mantle. Science 273(5281): 1528-1530.

Wen L X (2006). A compositional anomaly at the Earth's core-mantle boundary as an anchor to the relatively slowly moving surface hotspots and as source to the DUPAL anomaly. Earth Planet Sci Lett 246(1-2): 138-148.

Yuen K and Peltier W R (1980). Mantle Plumes and the stability of the $\mathrm{D}^{\prime \prime}$ layer. Geophys Res Lett 7(9): 625628 . 